\title{
Fire testing of external combustible ship surfaces
}

\author{
FRANZ EVEGREN, MICHAEL RAHM, MAGNUS ARVIDSON, and TOMMY HERTZBERG \\ Fire Technology \\ SP Technical Research Institute of Sweden \\ Box 857, SE-501 15 Borås \\ SWEDEN
}

\begin{abstract}
Reduced weight makes use of fiber reinforced polymer composite desirable in maritime construction applications. Exterior ship surfaces in combustible materials are although not covered by fire safety regulations and their fire protection is therefore a key issue. This paper reports how SP FIRE 105, a standardized test method for testing reaction to fire properties of façade systems, was adjusted and used to evaluate the potential for fire growth on external combustible ship surfaces; in particular fiber reinforced polymer composite surfaces protected with active or passive measures. The trials show that the test method is highly suitable but that some adjustments could be made to reduce uncertainties; in particular to use a gas burner instead of a heptane pool fire source and to add a strong criterion for when to activate active measures. Further efforts should also be made to develop suitable performance criteria, which were suggested to be based on the produced heat and the gas temperatures at the top of the panel.
\end{abstract}

KEYWORDS: fire spread, fire growth, external surfaces, fire protection, FRP composite, test method.

\section{NOMENCLATURE LISTING}

$\begin{array}{llll}c_{p} & \text { specific heat }(\mathrm{J} /[\mathrm{kg} \cdot \mathrm{K}]) & u & \text { velocity }(\mathrm{m} / \mathrm{s}) \\ d & \text { thickness }(\mathrm{m}) & x & \text { characteristic length }(\mathrm{m}) \\ h_{c} & \text { convective heat transfer coefficient }\left(\mathrm{W} / \mathrm{m}^{2} \mathrm{~K}\right) & & \\ \dot{q}_{i n c}^{\prime \prime} & \text { incident radiation }\left(\mathrm{W} / \mathrm{m}^{2}\right) & \text { Greek } \\ T_{f} & \text { film temperature }(\mathrm{K}) & \varepsilon & \text { emissivity }(-) \\ T_{g} & \text { gas temperature }(\mathrm{K}) & \rho & \text { density }\left(\mathrm{kg} / \mathrm{m}^{3}\right) \\ T_{s} & \text { surface temperature }(\mathrm{K}) & \sigma & \text { Stefan-Boltzmann constant }\left(\mathrm{W} /\left[\mathrm{m}^{2} \mathrm{~K}^{4}\right]\right)\end{array}$

\section{INTRODUCTION}

Authorities, the public and customers are increasingly demanding sustainable designs. The shipping industry still has great potential to reduce its environmental impact, which is strongly associated with the use of fossil fuels. The increasing focus on environmental competitiveness and energy efficiency gives lightweight designs a competitive advantage. Lightweight construction applications at sea (LASS) was a research project aimed at improving the efficiency of maritime transport by developing and demonstrating techniques for using lightweight materials for ship construction [1,2]. The project showed that by using fiber reinforced polymer (FRP) composite in merchant ships, a reduction in structural weight of up to $60 \%$ is achievable. Particularly the potential for significantly reduced fuel consumption makes FRP composite an appealing maritime construction material. However, the prescriptive fire safety regulations of the International Convention for the Safety of Life at Sea (SOLAS) [3] do not allow use of combustible materials in structural parts of a ship. The reformation of the fire safety chapter in 2002 although opened up for alternative solutions and performance-based design of fire safety, as described in SOLAS chapter II-2 Regulation 17. Alternative design solutions were now to be accepted if they were shown to provide a degree of safety not less than that achieved by compliance with the prescriptive requirements [4].

Fire safety evaluations of different FRP composite construction applications were performed as part of the European research project BESST (Breakthrough in European Ship and Shipbuilding Technologies, financed within the Seventh Framework Programme). These evaluations were risk-based [5], performed based on guidelines from the International Maritime Organization (IMO) [6], and were initiated by substantial hazard identifications [7]. They indicated that the key areas which have to be addressed with regards to fire safety when using FRP composite on ships are fire growth, generation of toxic smoke, added fire load as well as loss of structural integrity. Connected to all of these fire hazards there are performance 
requirements in SOLAS (chapter II-2/Reg. 5, 6, 9 and 11) which could be managed for interior spaces, e.g. by fitting thermal protection on all interior FRP composite surfaces. This was previously verified by standardized small and large scale fire tests [2] and, where necessary, experimental full scale fire tests [8] as part of the LASS project. However, if the FRP composite construction includes exterior surfaces, these need special attention. Combustible exterior surfaces could rapidly spread a fire to other decks and fire zones of the ship and could lead to e.g. collapse of structures and debris falling over life boats. Even though the properties of exterior surfaces are imperative they fall outside the scope of current regulations, which "assume" non-combustible exterior surfaces [9]. This paper reports how the standardized test method SP FIRE 105 [10] was adjusted and used to evaluate fire growth on external combustible ship surfaces; in particular external FRP composite constructions with active or passive safety protection on the surfaces.

\section{METHOD}

For materials used in maritime applications there is a standardized IMO method for testing the potential for fire growth, called "Test for surface flammability" and often referred to as the "spread of flame" test. It is a small scale test described in part 5 of the FTP Code [11] which is based on ISO 5658-2 [12] and applies to interior surfaces. In the test, a sample of the surface is exposed to a heated panel. The specimen is set up at an angle with the panel which gives a decreasing irradiation exposure along the sample surface. Fire is initiated by a pilot flame where the irradiation intensity is the highest. The maximum distance of the horizontal flame spread (i.e. the point determining the lowest irradiation level for sustained combustion) and the produced heat are used to quantify the sample properties. This small-scale method is the only standardized method which evaluates fire-spread characteristics of materials used on ships. However, for large exterior surfaces where the fire source could develop over time, vertical fire spread is possible, and convective heat from flames plays a big role this small scale method may not be representable.

On land on the other hand, fire spread on combustible external walls has been studied at least the last half decade [13-19] and several test methods have been proposed through the years [20]. One of these is the "Swedish test method" called SP FIRE 105 [10]. It was initially developed from a small scale method introduced in 1958 with reference to correlations with large scale tests [21]. The test method was significantly revised during the eighties due to lack of a criterion for fire spread through a window on the next floor above and an anticipation of more intense fires due to new materials [15-16]. The amended method for testing reaction to fire properties of façade systems [10] was released in 1985 and also included an increase in size of the sample; hence it became a large scale test. Currently the method is standardized in Sweden, Denmark, and Norway and has been proposed to be a certifiable method internationally [22-24]. This method was altered to evaluate fire growth on external combustible ship surfaces, as described below.

\section{SP FIRE 105 façade test rig}

The SP FIRE 105 [10] test method specifies a procedure to determine reaction to fire properties of different assemblies of materials, insulation, and claddings when exposed to fire from a simulated apartment fire where flames emerge through a large window opening. The test rig consists of a $150 \mathrm{~mm}$ thick lightweight concrete wall, $4000 \mathrm{~mm}(\mathrm{~W})$ by $6000 \mathrm{~mm}(\mathrm{H})$, above a fire compartment with a $3000 \mathrm{~mm}(\mathrm{~W})$ by 710 $\mathrm{mm}(\mathrm{H})$ front opening. The compartment also has a horizontal opening in the floor, close to its back wall, for air intake that measures $3140 \mathrm{~mm}(\mathrm{~W})$ by $300 \mathrm{~mm}$ (D). The fire source consists of two trays positioned next to each other, each measuring $1000 \times 100 \times 500 \mathrm{~mm}(\mathrm{WxHxD})$. A flame suppressing lattice is fitted on top of the tray edges and after each tray has been filled with 30 liters of heptane, water is added such that the fuel level is touching the underside of the lattice. Figure 1 shows the dimensions of the fire rig and the position of the fire trays inside the fire compartment.

\section{Arrangement with FRP composite panels and reference boards}

Instead of a regular building façade system, tests were performed with FRP composite panels and with noncombustible calcium silica boards, as a reference. The FRP composite panels had a sandwich structure with glass fiber reinforced polyester face laminates and a cross linked PVC foam core. The thickness of the laminates was $1.7 \mathrm{~mm}$ and the thickness of the core $\left(80 \mathrm{~kg} / \mathrm{m}^{3}\right)$ was $50 \mathrm{~mm}$. The sandwich panels were vacuum infused in one shot with resin distribution by grooves in the core. The laminate fiber fraction was about $50 \%$ by volume and of the resin about $1500 \mathrm{~g} / \mathrm{m}^{2}$ was absorbed by the core. Three separate panels measuring $4000 \mathrm{~mm}(\mathrm{~W})$ by $2150 \mathrm{~mm}(\mathrm{H})$ made up each façade sample, giving an overall size of 4000 
$\mathrm{mm}(\mathrm{W})$ by $6450 \mathrm{~mm}(\mathrm{H})$. They were attached on the lightweight concrete wall, leaving an air gap of about $50 \mathrm{~mm}$, and covered the two fictitious windows, as illustrated in Fig. 1. In order to prevent fire spread to the backside of the specimens, a nominally $10 \mathrm{~mm}$ thick non-combustible Promatect ${ }^{\circledR}$ board was used to cover the gap and the bottom end of the test specimens. In the free burn reference test, non-combustible nominally $10 \mathrm{~mm}$ thick Promatect ${ }^{\circledR}$ boards were used instead of FRP composite panels. Each board measured $1250 \mathrm{~mm}(\mathrm{~W})$ by $3000 \mathrm{~mm}(\mathrm{H})$, giving a total area of $3750 \mathrm{~mm}(\mathrm{~W})$ by $6000 \mathrm{~mm}(\mathrm{H})$.

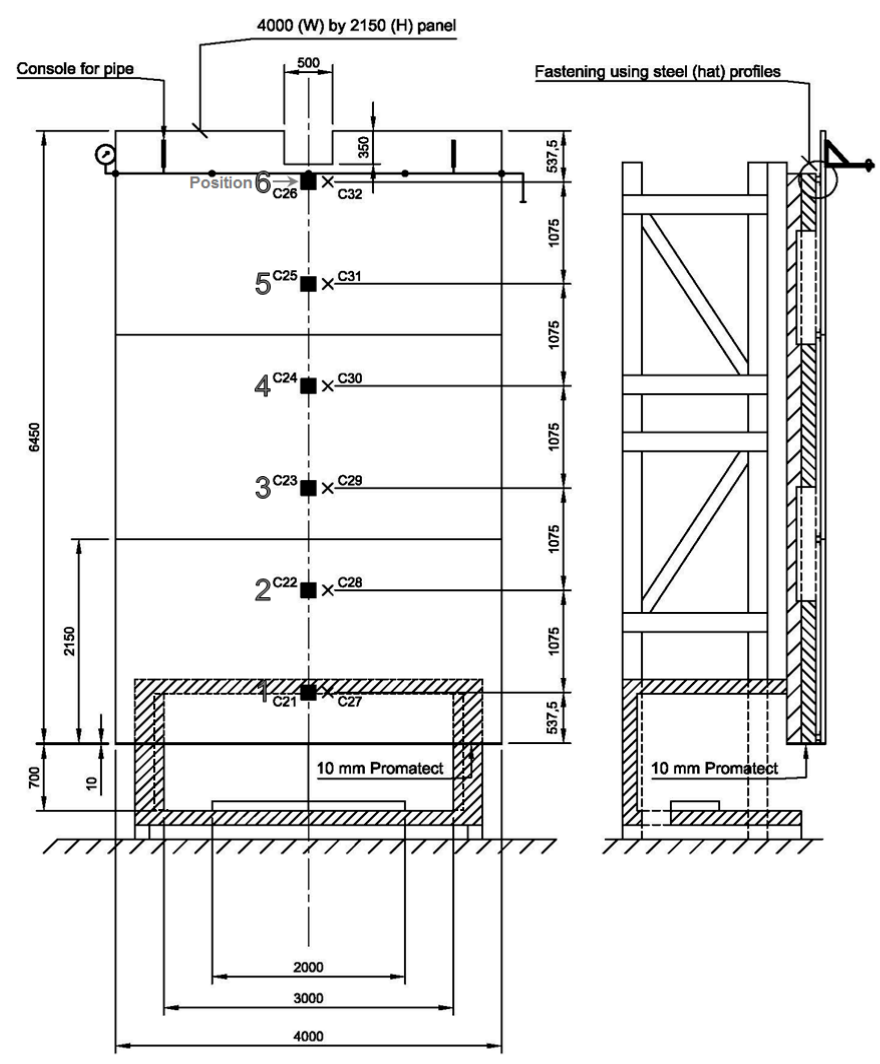

Fig. 1. Experimental setup, dimensions and instrument positions.

\section{Instrumentation and measurements}

The thermal exposure of the panel surface was measured using nominally $0.7 \mathrm{~mm}$ thick, $150 \mathrm{~mm}$ by $150 \mathrm{~mm}$ Inconel steel plates with wire thermocouples spot-welded on their backside. The steel plates were fastened flush with the surface and covered a hole $(\varnothing 100 \mathrm{~mm})$ drilled through the panels for the thermocouple wires. The gas temperature was measured along the centerline of the panels using $\varnothing 0.50 \mathrm{~mm}$ sheathed type $K$ thermocouples. The bead of each thermocouple was positioned $50 \mathrm{~mm}$ from the front surface of the panels and $50 \mathrm{~mm}$ offset the surface temperature measurement steel plates. In total, six surface temperature measurement steel plates and six gas measurement thermocouples were installed, as illustrated in Fig. 1. For the reference test with non-combustible boards the instruments were installed at the same position as in the tests with the FRP composite panels. The tests were conducted under an Industrial Calorimeter where measurements of gas temperature, velocity, and generation of gaseous species such as $\mathrm{CO}_{2}$ and $\mathrm{CO}$ and depletion of $\mathrm{O}_{2}$ were made. Based on these measurements, both the convective and the total heat release rate can be calculated.

\section{Active and passive protective measures}

Trials were performed where the FRP composite panels were protected with active or passive measures. As an active fire safety measure, a water application system referred to as a drencher system was designed, consisting of a 11/4" (nominally $32 \mathrm{~mm}$ ) steel pipe with outlets every $1000 \mathrm{~mm}$. The pipe was fed from one end and a pressure transducer was positioned at the opposite end, i.e. at the hydraulically most remote position. The pipe was installed horizontally with five flat spray nozzles, manufactured by BETE Fog 
Nozzle Inc., distributing water at the top of the set-up. These nozzles produce a thin, flat sheet of water spray which covers a narrow area. The middle nozzle was positioned in front of the vertical centerline of the set up and the two outermost nozzles were hence positioned in front of the vertical edges of the panels, i.e. the panels were reached by water from an average of "four" nozzles (see Fig. 1).

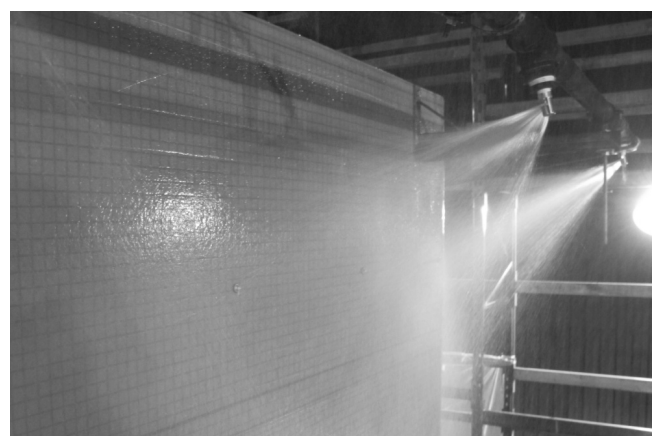

Fig. 2. Experimental setup with the drencher system.

The nozzles were installed in a pendent orientation with a spray angle of $145^{\circ}$. The pipe was installed such that the water spray from the nozzles hit an imaginary horizontal line $450 \mathrm{~mm}$ below the top of the set-up, as illustrated in Fig. 2. The area below this line, which corresponds to the total coverage area of the nozzles, hence equaled $4000 \mathrm{~mm}(\mathrm{~W})$ by $6000 \mathrm{~mm}(\mathrm{H})$. This area was used for the calculation of the design discharge density. The total water flow rate was measured with a Krohne 0-200 L/min water flow meter and the water pressure at the end of the pipe was measured using a $0-16$ bar pressure transducer. Table 1 shows the specific nozzles used, their $\mathrm{K}$ factors, the specific design discharge densities, and the corresponding water flow rates. The design discharge density is expressed in $\mathrm{mm} / \mathrm{min}$, which equals liter/(min $\left.\mathrm{m}^{2}\right)$. The nominal water pressure was calculated based on the $\mathrm{K}$ factor of the particular nozzle.

Table 1. The flat spray nozzles used in the tests.

\begin{tabular}{|c|c|c|c|c|c|c|}
\hline $\begin{array}{l}\text { Design discharge } \\
\text { density } \\
{[\mathrm{mm} / \mathrm{min}]}\end{array}$ & $\begin{array}{l}\text { Nozzle } \\
\text { name }\end{array}$ & $\begin{array}{c}\text { K-factor } \\
{\left[\left(1 / \mathrm{min}^{2} / \mathrm{bar}^{1 / 2}\right]\right.}\end{array}$ & $\begin{array}{l}\text { Design } \\
\text { flow rate } \\
{[\mathrm{L} / \mathrm{min}]^{\mathrm{a}}}\end{array}$ & $\begin{array}{l}\text { Total water } \\
\text { flow rate } \\
{[\mathrm{L} / \mathrm{min}]^{b}}\end{array}$ & $\begin{array}{c}\text { Flow rate } \\
\text { per nozzle } \\
\text { [L/min] }\end{array}$ & $\begin{array}{c}\text { Calculated } \\
\text { water pressure } \\
\text { [bar] }\end{array}$ \\
\hline 2 & FF187 & 13.7 & 48 & 60 & 12 & 0.76 \\
\hline 3 & FF209 & 18.2 & 72 & 90 & 18 & 0.98 \\
\hline 4 & FF250 & 23.9 & 96 & 120 & 24 & 1.00 \\
\hline
\end{tabular}

aBased on the design discharge density multiplied by the flow from "four" nozzles.

${ }^{\mathrm{b}}$ Based on the flow rate from all five nozzles.

The passive fire safety measure consisted of a system called LEO, developed by Saertex. It consists of special glass fiber reinforcement, infusion resin, and top coat loaded with fire retarding additives. The infusion resin behaves like standard polyester but with a slightly higher viscosity than normal infusion resins. The top coat is intumescent and applied manually by roller at a layer thickness of about $1 \mathrm{~mm}$, weighing about $1.3 \mathrm{~kg} / \mathrm{m}^{2}$. The sandwich panels were manufactured with the same thicknesses, fiber fractions, and resin absorption as the standard panels.

\section{RESULTS}

Trials were performed with FRP composite panels protected with the active or passive protective measures described above. A total of four tests were performed with different drencher system setups. One test was carried out with each design discharge density, where the drencher system was activated when major parts of the FRP composite surface were involved in the fire. One test was also performed where the drencher system with a design discharge density of $3 \mathrm{~mm} / \mathrm{min}$ was pre-activated. With the passive fire protective coating (LEO) one test was carried out. Except from these tests, one reference test was carried out with non-combustible Promatect ${ }^{\circledR}$ boards instead of FRP composite panels. The intent of the test was to provide benchmark data for comparison of heat release rate, gas temperature, and surface temperature measurements. 
It should be noted that in the subsequent presentation of measurements from the six tests, the time scale has been adjusted. The incipient phase of the fire development in the heptane trays was not repeatable and the actual growth phase thus came sooner in some tests than in others. For comparison reasons, the time scale was therefore adjusted such that the starting times $(t=0)$ in the below records correspond to the time when the total heat release rate reached $100 \mathrm{~kW}$. The incipient times cut off are detailed further in Table 3 .

\section{Heat release rate}

The heat release rates measured over time in the reference test (non-combustible) and in the tests with drencher systems with different design discharge densities are presented in Fig. 3.

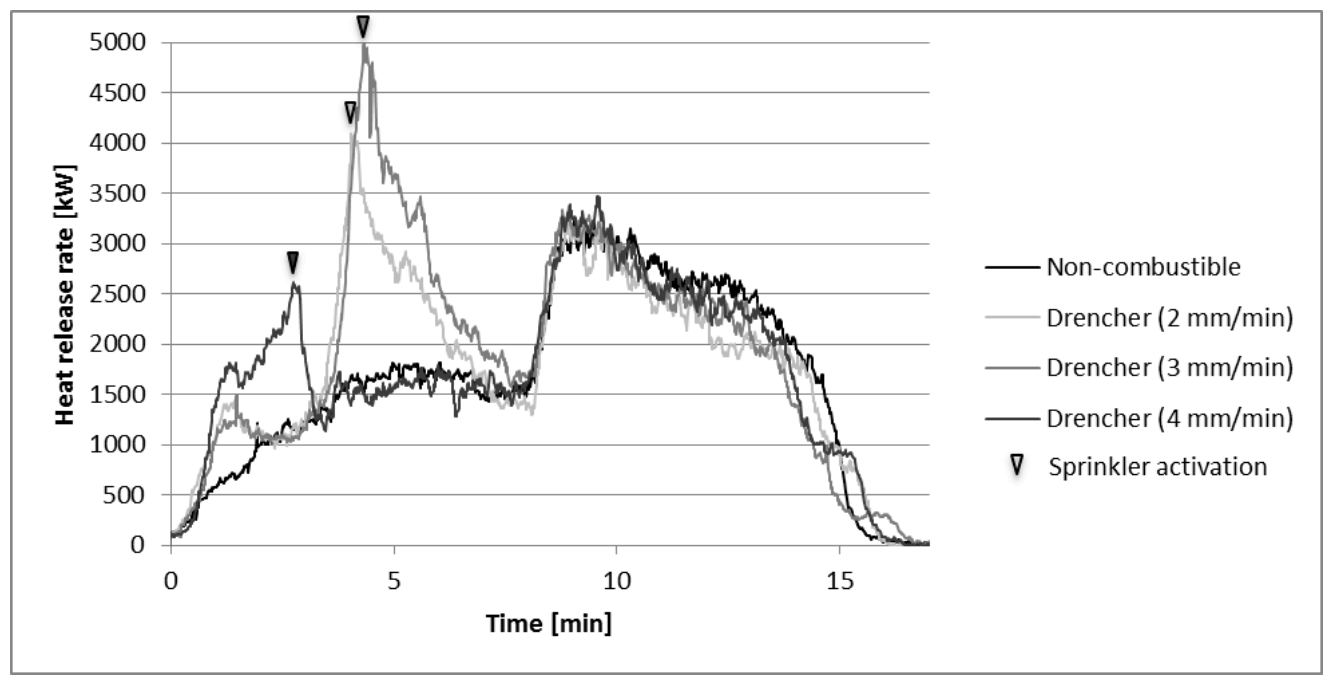

Fig. 3. Heat release rate histories of reference test and tests with drencher system with different discharge.

The test with non-combustible Promatect ${ }^{\circledR}$ boards instead of FRP composite panels was a free burn fire test without application of water or any other installed fire protective measures. In summary, the heat release rate peaked at approximately $1800 \mathrm{~kW}$ after about five minutes and then declined to a level around 1500 $\mathrm{kW}$ in the following minutes. After approximately eight minutes, the fire developed rapidly to a peak at around $3000 \mathrm{~kW}$. This second peak lasted for about two minutes before the fire gradually declined as the amount of fuel in the trays decreased. Thus, this estimated the fire exposure from the fire source alone.

The first test conducted with FRP composite panels was with a drencher system having a design discharge density of $3 \mathrm{~mm} / \mathrm{min}$. The application of water was started when it was judged that the majority of the vertical FRP composite surface was involved in fire. This gave a maximum heat release rate of almost $5000 \mathrm{~kW}$ but the application of water suppressed the fire in the FRP composite panels almost immediately. Due to the characteristics of the fire source mentioned above, the fire reached a second peak in similarity with the reference test. The actual involvement of the panels was marginal at this phase of the fire.

In the following test with FRP composite panels the design discharge density was increased to $4 \mathrm{~mm} / \mathrm{min}$. The application of water was unfortunately started at a significantly earlier stage of the fire in comparison with the test with $3 \mathrm{~mm} / \mathrm{min}$. The delay in the HRR measurements in combination with a rapid fire development when the FRP composite panels were involved at an earlier stage made it difficult to time the sprinkler activation. The total heat release rate was slightly over $2500 \mathrm{~kW}$ at the start of water application and the fire in the FRP composite panels was immediately suppressed. A second peak was obtained similar to the one in the reference test but, as in all of the tests with drencher systems, the actual involvement of the FRP composite panels during this phase was marginal.

For the third test with FRP composite panels, the design discharge density was decreased to $2 \mathrm{~mm} / \mathrm{min}$. The attempt to start the application of water at a heat release rate similar to that in the test with $3 \mathrm{~mm} / \mathrm{min}$ was more successful than in the previous test. The initial fire growth rate was very similar to that in the test with $3 \mathrm{~mm} / \mathrm{min}$, indicating that the FRP composite panels were involved in the fire in a similar fashion. The total heat release rate was approximately $4000 \mathrm{~kW}$ at the start of water application, i.e. slightly lower than in the test with $3 \mathrm{~mm} / \mathrm{min}$. The fire reached a second peak similar to the one in the reference test. 
Thereafter the tests with the pre-activated drencher system with a discharge density of $3 \mathrm{~mm} / \mathrm{min}$ and with the fire protective coating (LEO) were carried out. The heat release rate histories from these tests are presented in comparison with the reference test (non-combustible) and the previous test with a drencher system with a design discharge density of $3 \mathrm{~mm} / \mathrm{min}$ in Fig. 4.

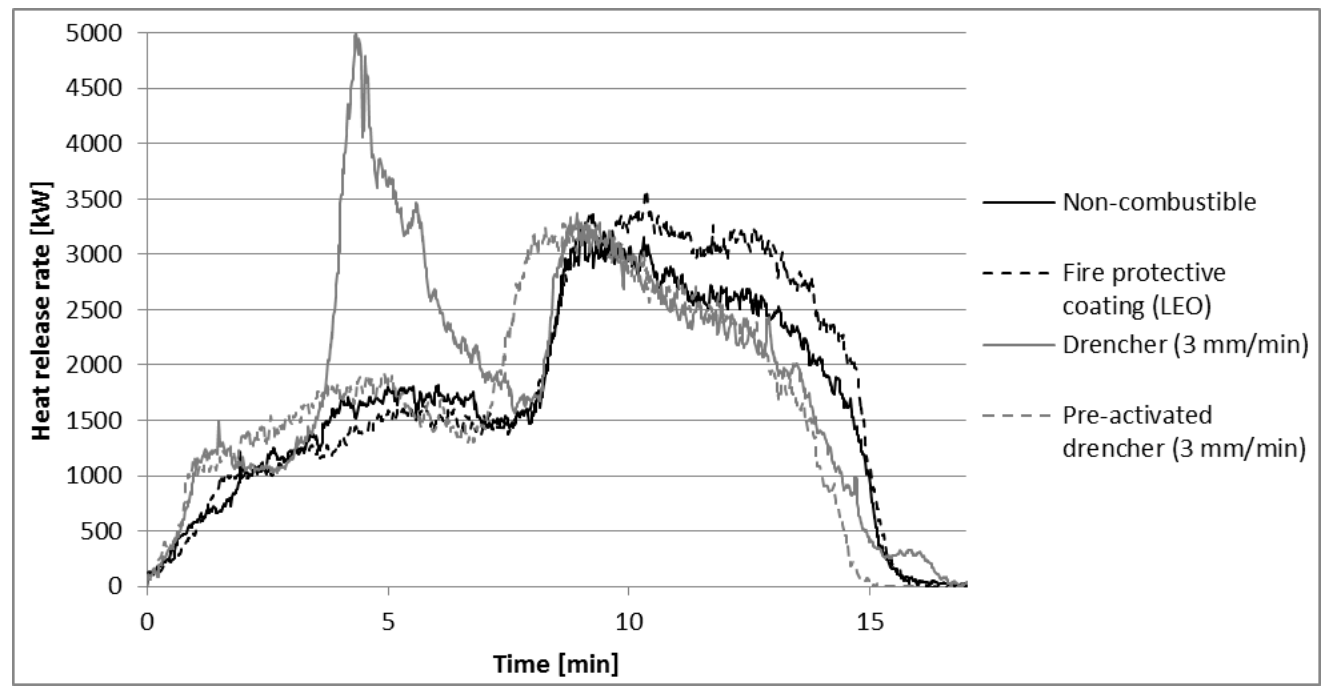

Fig. 4. Heat release rate histories of reference test and tests with different set-ups of safety measures.

The test with a pre-activated drencher system with $3 \mathrm{~mm} / \mathrm{min}$ was performed very similar to the test where the same system was not pre-activated. The only difference was that the water flow was initiated prior (90 seconds) to fire ignition. The intent was to simulate a premature activation of an exterior drencher system and to investigate whether the design discharge density of $3 \mathrm{~mm} / \mathrm{min}$ was sufficient to prevent fire ignition and fire spread in the FRP composite panels. In the test, the incipient phase (below $100 \mathrm{~kW}$ ) of the fire development was significantly longer in comparison with the previous tests and hence gave more preheating to the fuel. Thereafter the fire growth up to $1800 \mathrm{~kW}$ was faster, which in all gave a slightly shifted heat release rate curve in comparison with the other tests. Accounting for this shifting, the heat release rate was very similar to that of the reference test. After reaching the first peak of about $1800 \mathrm{~kW}$, the fire decreased for a few minutes before increasing rapidly to a level of about $3100 \mathrm{~kW}$. The different stages of the fire are illustrated in Fig. 5 and the damages after the test are illustrated in Fig. 8.

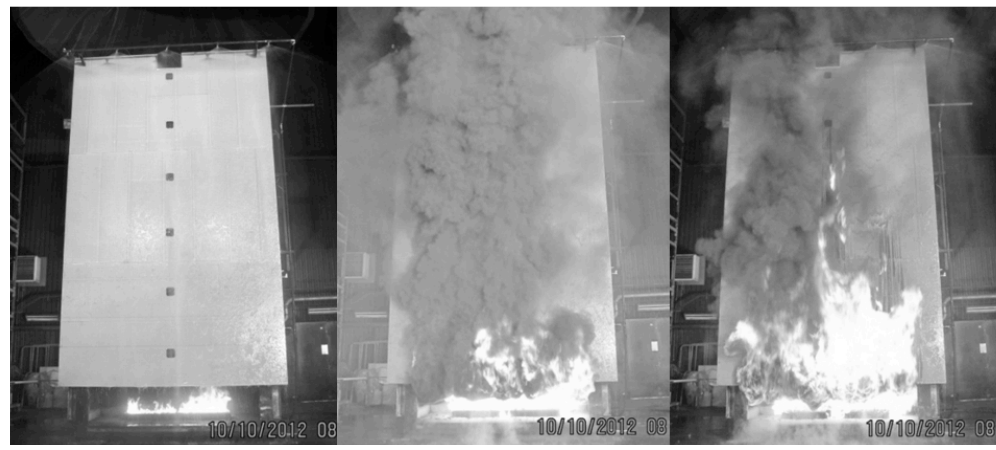

Fig. 5. Snapshots of the fire test with pre-activated drencher soon after ignition and after 5 and 10 minutes.

The final test was performed with the passive fire protective coating referred to as the LEO system. The intent of the test was to compare the fire development with both the untreated standard FRP composite panels (before the drencher system was activated in the tests with drencher) and the free burn reference test involving non-combustible boards. In summary it was observed that the LEO system delayed ignition and fire involvement of the FRP composite panels until the fire reached its second peak. Once burning, the energy contribution from the panels gave a $10 \%$ higher heat release rate than the reference test (averaged between 9 and 15 minutes). Furthermore, it was noted that as the heat produced by the heptane decreased, 
the added heat release from the panels decreased in the same proportion. The last remaining fire in the FRP composite panel self-extinguished a few minutes after the heptane had burnt out.

\section{Gas and surface temperatures}

The gas temperature recordings were, as well as the measured surface temperatures, dependent on if and when water was applied. The second phase of the fire tests where the fire developed in a more intense way is therefore most valid for test-to-test comparisons, since it is independent of the time before and soon after water application (if applied).

From the recordings it could be observed that higher average temperatures were reached in the free burn fire test with non-combustible panels than in any test with drencher. This shows that the flowing water indeed provided cooling of the panels. Comparing the average temperatures between the tests with non-preactivated drencher systems showed that the temperatures were very similar. The gas temperatures were generally lower in these tests than in the test where the drencher system was pre-activated. The average surface temperatures were although at comparable levels in all tests with drencher systems. The overall highest average surface and gas temperatures were recorded in the test with the LEO system. This is associated with the combustion of FRP composite during the considered time of the fire test. However, it should be noted that no water was applied.

The surface temperature measurements along the centerline (see Fig. 1 and Fig. 5) were also used to characterize the heat exposure further. The approximate maximum incident radiation $\dot{q}_{i n c}^{\prime \prime}\left[\mathrm{kW} / \mathrm{m}^{2}\right]$ was estimated using the surface temperature $T_{s}[\mathrm{~K}]$ of the plate thermocouples and the nearby measured gas temperature $T_{g}[\mathrm{~K}]$ according to the simplified expression in Eq. 1 [25]:

$$
\dot{q}_{i n c}^{\prime \prime}=\sigma T_{s}^{4}-\frac{h_{c}\left(T_{g}-T_{s}\right)}{\varepsilon}+\frac{d c \rho}{\varepsilon} \cdot \frac{d T_{s}}{d t},
$$

where $\sigma$ is the Stefan-Boltzmann constant, $d$ is the plate thickness, $c$ is its specific heat, $\rho$ its density and is the emissivity of the plate surface. Values were inserted for the plate thermocouple thickness $(0.7 \mathrm{~mm})$, the Stefan-Boltzmann constant $\left(5.67 \cdot 10^{-8} \mathrm{~W} /\left[\mathrm{m}^{2} \mathrm{~K}^{4}\right]\right)$, the specific heat of steel $\left(480 \mathrm{~kg} / \mathrm{m}^{3}\right)$ as well as for the density of steel $(7850 \mathrm{~J} /[\mathrm{kg} \cdot \mathrm{K}])$. The emissivity was assumed to $0.9[-]$ and the convective heat transfer coefficient, $h_{c}\left[\mathrm{~W} /\left(\mathrm{m}^{2} \mathrm{~K}\right)\right]$, was estimated by the expression in Eq. 2, valid for forced convection between air and steel [26]:

$$
h_{c}=2.4 T_{f}^{0.085} \cdot u_{\infty}^{1 / 2} \cdot x^{-1 / 2}
$$

where $u$ is the velocity of the vertical air flow and $x$ is a characteristic length. The velocity was estimated to $6 \mathrm{~m} / \mathrm{s}$ based on video recordings of the reference test and the characteristic length was set to $0.2 \mathrm{~m}$, i.e. the side measurement of the square thermocouple plates. The film temperature, $T_{f}[\mathrm{~K}]$, is defined as the average of the surface temperature, $T_{s}$, and the temperature of the free air flow, i.e. the gas temperature, $T_{g}$. Thus, the incident radiation could be determined as a function of the height above the bottom edge of the specimen, as presented in Fig. 6. Note that since the velocity in actuality varies along the height of the specimen, the incident radiation will be slightly overestimated close to the fire source and somewhat underestimated higher up.

\section{Fire damage}

In the reference test with non-combustible panels there were no fire damages except an almost entirely blackened surface (by soot) and some loosened connections between the panels (causing small gaps). In the first test conducted with FRP composite panels, the fire was allowed to progress the longest before activation of the drencher system, which in this case had a design discharge density of $3 \mathrm{~mm} / \mathrm{min}$. Fire damages were primarily concentrated to the area on the left of the vertical centerline of the set-up, indicating that the flame had tilted to the left, rather than being perfectly vertical. The outer laminate had 
damages from burning in a triangular shaped area of approximately $3000 \mathrm{~mm}$ (W) by $6000 \mathrm{~mm}(\mathrm{H})$, i.e. to the top of the set-up. To the left and right of this area, the panels were blackened and scorched, as illustrated in Fig. 8. The core was severely damaged in a rectangular shaped area of approximately 1700 $\mathrm{mm}(\mathrm{W})$ by $2150 \mathrm{~mm}(\mathrm{H})$. The following tests with non-pre-activated drencher systems had similar damages of different size, as précised in Table 2, with the exception that the core was slightly more deteriorated in the test with $2 \mathrm{~mm} / \mathrm{min}$. In the test with a pre-activated drencher system the damages were more defined and consisted of three triangles, as shown in Fig. 8, out of which only the middle damage included deterioration of the core.

Table 2. Approximate triangular damage in the drencher tests (denoted by height and base width).

\begin{tabular}{|c|c|c|c|c|} 
Damage & $\mathbf{2} \mathbf{~ m m} / \mathbf{m i n}$ & $\mathbf{3} \mathbf{~ m m} / \mathbf{m i n}$ & $\mathbf{4} \mathbf{~ m m} / \mathbf{m i n}$ & $\mathbf{3} \mathbf{~ m m} / \mathbf{m i n}$ (pre-activated) \\
\hline Scorched area & $6.0 ; 2.9$ & $6.0 ; 3.5$ & $5.8 ; 3.3$ & $4.0 ; 0.8$ \\
\hline Laminate damages & $6.0 ; 2.5$ & $6.0 ; 3.0$ & $5.8 ; 3.0$ & $4.0 ; 0.8+2.3 ; 0.85^{\mathrm{a}}$ \\
\hline Core damages & $2.5 \times 2.0^{\mathrm{b}}$ & $2.15 \times 1.7^{\mathrm{b}}$ & $0.65 \times 0.15^{\mathrm{b}}$ & $2.0 ; 0.6$ \\
\hline
\end{tabular}

${ }^{\mathrm{a}}$ The damage consisted of one large and two smaller triangular damages.

${ }^{\mathrm{b}}$ Denotes a rectangular damage.

In the final test with fire protective coating, fire damages were primarily concentrated to a triangular area of approximately $2500 \mathrm{~mm}(\mathrm{~W})$ extending almost the full height of the set-up. Of the three panels that formed the test specimen, the outer layer of the bottommost panel had expanded approximately $10 \mathrm{~mm}$. The upper 10-15 $\mathrm{mm}$ of the core of the top panel was charred but showed no signs of burning. The middle panel had a severely charred core down to $20-25 \mathrm{~mm}$ but showed no signs of burning. The bottom panel was severely charred down to $25-35 \mathrm{~mm}$ and had probably been burning. The core of this particular panel had expanded significantly.

\section{DISCUSSION}

Below follow discussions regarding the suitability of the test method SP FIRE 105 to evaluate the potential for fire growth of combustible external ship surfaces. In particular the possibility to evaluate surfaces protected with passive or active measures is discussed as well as suggestions for criteria.

\section{The fire exposure and its relevance}

In all of the above documented tests, two distinct phases could be distinguished with regards to fire exposure from the test rig. This was illustrated for example in Fig. 3, where the fire source reaches a heat release rate of about $1700 \mathrm{~kW}$ in the first phase. Thereafter it drops slightly before rapidly reaching the second phase and a level of about $3000 \mathrm{~kW}$. After a short period at this level the heat release rate decreases before the heptane runs out. The rapid development between the phases could be explained by the heptane starting to boil as the heat in the fire compartment reaches a significant level. The combined effect could then cause an intense pyrolysis and combustion of heptane which gives the rapid increase in heat release rate. The limitation in maximum HRR mainly depends on the size of the heptane trays (fuel surface) and the ventilation openings of the fire compartment which affect the heat exposure and vaporization of fuel.

With regards to this stage-like fire exposure scenario it is relevant to consider another fire test used for materials in maritime applications, namely the test for fire-restricting materials for high speed crafts (HSC). Fire restricting materials are required for many interior surfaces and furniture according to the HSC Code [28]. The fire test is described in part 10 of the FTP Code [11] and is based on ISO 9705 [28], often referred to as the "room corner test". In this test, the material to be tested is mounted on walls and ceiling of a full scale room and a propane gas burner positioned in one of the inner corners provides a $100 \mathrm{~kW}$ fire for 10 minutes, followed by a $300 \mathrm{~kW}$ output for an additional 10 minute period. This is supposed to represent a preheating stage where contribution to fire growth is evaluated, followed by exposure to a significant fire, in magnitude with a flashover. Since the fire source most often consists of an internal fire, this stage-like fire scenario is fully relevant also for exterior surfaces.

Despite the potential relevance of a varying level of fire exposure it should be noted that such distinct levels are not always present when carrying out tests according to SP FIRE 105. In [23] for example, the heat release rate in a blank reference test (F0) quickly reached about $1500 \mathrm{~kW}$ but then continuously 
increased to about $2500 \mathrm{~kW}$ before the heptane seemingly ran out. Similar fire developments have also been observed at SP Fire Technology, using the same fire rig as in the trials documented above. In the numerous tests carried out at SP Fire Technology over the years is has although been noted that the characteristics of the fire development are generally the same within series of trials, as above. It indicates that the difference could depend on e.g. conditions in the test hall (humidity, ambient temperature, ventilation etc.) or other details in the test set-up, such as a not fully perpendicular test rig or an angle of the fire trays. Over the whole scenarios, the fire exposures could although be claimed similar, regardless of the uncertainty of the characteristics of the fire development, considering the heat release rate in combination with the duration, i.e. the heat dose.

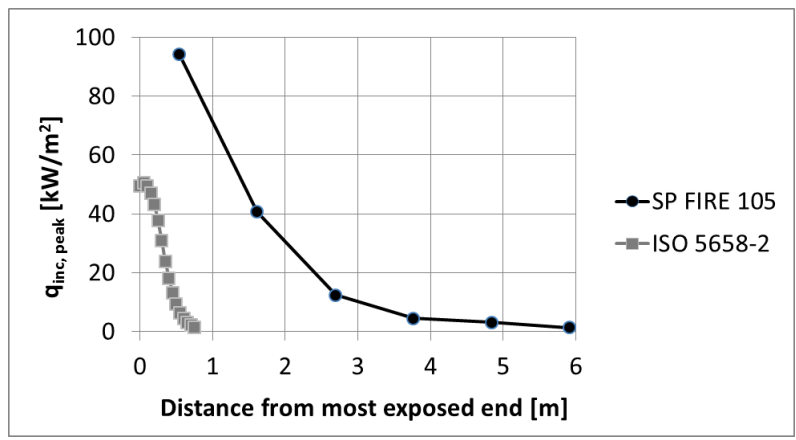

Fig. 6. Calculated maximum incident radiation during the reference test with non-combustible boards.

The calculated maximum incident radiation presented in Fig. 6 indicates a decreasing heat exposure along the specimen surface, similar to the decreasing incident radiation exposure of the sample in the standardized IMO test for surface flammability [11]. The level of incident radiation exposure along the specimen surface in this test is described in the test procedures $[11,12]$ and is presented next to the incident radiation exposure along the specimen surface in the façade test according to SP FIRE 105 in Fig. 6. From this comparison it is clear that the full scale test method covers the incident radiation interval which the specimen is exposed to in the small scale method and exceeds it by far. The incident radiation exposure is although spread out over an about ten times greater distance of the specimen in the large scale test. An imperative difference between the test methods as such is also the orientation of the specimen, which in the façade rig is vertical and in the spread of flame rig is lateral. The vertical alignment is more severe from a fire spread perspective since this also includes exposure to convective heat from the flames. This is obviously very relevant when fire may spread to other decks and hence speaks for the need of a larger scale and vertically aligned test rather than the current test for surface flammability.

In maritime applications, the test generally considered to be the next step up from the test for spread of flame is the earlier mentioned room corner test, based on ISO 9705 [28]. This test is full scale and includes further complexities of a fire than the test for surface flammability [11]. Hence, the properties which are evaluated are also different. In particular the room corner test includes the significant effects of enclosure fire dynamics. That also generally makes the test harder to pass than the test for spread of flame; that is, materials which pass the room corner test generally also pass the test for spread of flame. This was for example the case with the fire protective coating, the LEO system, which was tested according to both methods in the BESST project. The ability to manage effects in enclosure fires could although be claimed irrelevant, as these effects will not appear out in the open on exterior surfaces. Hence, the room corner test, which is the next step up from the test for surface flammability, is neither well-suited for external ship surfaces.

The test method for external ship surfaces must capture the significant effects in a representative worst-case fire scenario. As the fire source is often an internal fire, the stage-like scenario which appeared in the façade test and which is simulated in the room corner test is highly relevant. The decreasing incident radiation exposure along the sample is relevant and of similar fashion compared to that in the test for spread of flame. The levels in the façade test are although higher, which must be considered when determining performance criteria. It also gives a more severe fire exposure since it includes convective heat. In summary, it could be concluded that the test method presented as SP FIRE 105 [10] is highly suitable to evaluate fire growth on external combustible ship surfaces. 


\section{Performance in trials and suggestions on criteria}

In the tests where a drencher system was activated when major parts of the FRP composite were involved in the fire it could be shown that this kind of system is suitable to extinguish an external fire. As displayed in Fig. 3, fire in the FRP composite panels was suppressed almost immediately when water was applied. After the drencher system was activated in the different tests, combustion of the FRP composite panels seemed to make an insignificant addition to the heat release rate, even when the fire source grew larger. However, the resulting damages, which must hence mainly have occurred before the sprinkler system was activated, were considerable and assessed to have caused a large area to loose structural integrity.

An interesting question is hence whether or not an early application of water can prevent fire ignition and fire damages to the panels? Investigations were made of the surface and gas temperatures along with the heat release rate recorded in the test with pre-activated drencher with a design discharge density of $3 \mathrm{~mm} / \mathrm{min}$. As illustrated in Fig. 7 they showed that the surface temperature at the bottommost position 1 stayed at similar high levels throughout the test, likely due to the significant exposure from the fire source. At position 2 the surface temperature had peaks above the ignition temperature of the current FRP composite panel (about $350^{\circ} \mathrm{C}$ ) and otherwise kept at the boiling point of water. At higher levels of the panel, the surface temperatures were quite steady around the boiling point of water, except from a couple of minor increases at the lower levels. These may depend on increased evaporation and other effects on the water from e.g. the plates above or fluctuations in the fire source. It was noted that the peaks in surface temperature seem to correlate with significant increases in the heat release rate. In particular position 2 seems to have experienced limitations in the coverage of water during the fire growth in the first phase and during the rapid increase to the second phase.

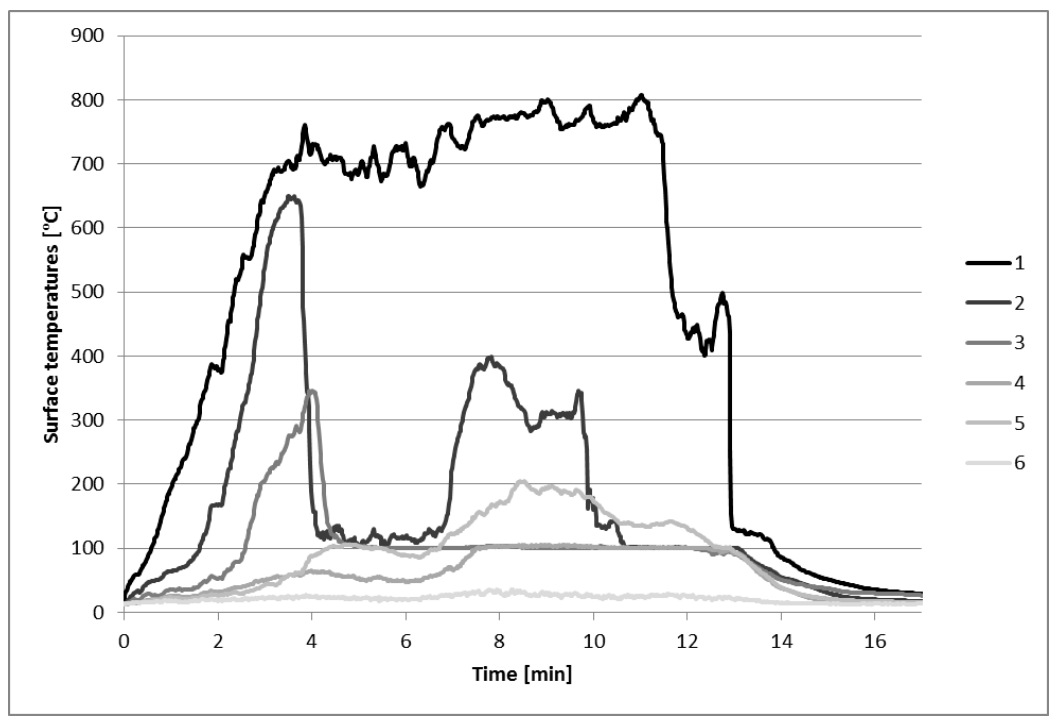

Fig. 7. Surface temperatures recorded at positions 1-6 during the test with pre-activated drencher.

In all it could be concluded that ignition could be avoided far down the FRP composite surface by preactivation of a water application system. Before stating specifically how far down this is valid it is although relevant to consider how close to such a large fire it is reasonable to expect protection and whether the caused damages are acceptable in the constructional design.

Excessing the ignition temperature in only a few occasions obviously gave correlations with the resulting damage. Comparing with the test where the same drencher system was activated after 4 minutes of fire growth above $100 \mathrm{~kW}$, the damages were significantly smaller when the drencher system was preactivated, which is also illustrated in Fig. 8. The areas where structural integrity was assessed lost covered a wide column throughout the full height of specimen when drencher activation was delayed, as compared to only a narrow streak in the middle of the bottommost panel with pre-activation. This could hence minimize the caused damages to an FRP composite panel. As mentioned above, it may although be hard to avoid that a small area closest to the fire source becomes damaged. The damaged area could instead work as a dimensioning damage input to calculations of structural strength. From Fig. 8 it may also be interesting to 
note how the overall damage pattern in the tests with drencher systems correlated with the water distribution pattern. Most fire damages occurred directly below the nozzles as the areas in-between were covered by overlapping water flows.

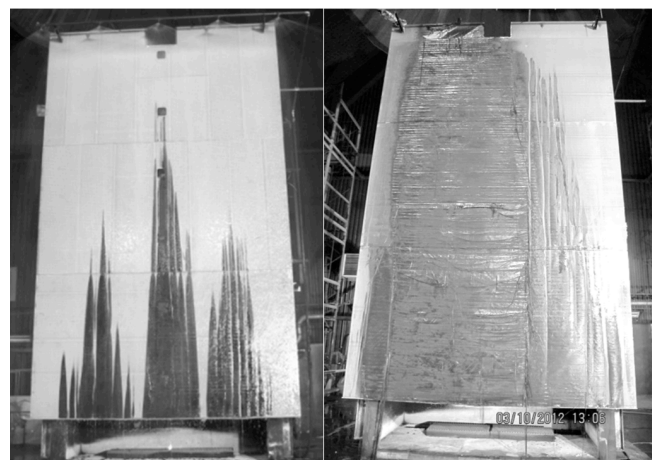

Fig. 8. Damages after tests where a drencher system had been pre-activated and activated after 4 minutes.

From the above discussions it could be concluded that early activation, or preferably pre-activation, is vital to avoid considerable damages to FRP composite surfaces when using protection by application of water. With regards to the damages to the FRP composite panels in the tests with drencher systems, the magnitude of the damages obviously stand in correlation with the pre-activation time. This determines the time of exposure and the reached peak heat release rate. However, as seen in Fig. 3 the developed heat release rate at the time of activation of the drencher systems differed quite a lot between the tests. The gradients of the HRR curves at the time for activation indicate that the magnitude is very sensitive to timing. The drencher system with a design discharge density of $2 \mathrm{~mm} / \mathrm{min}$ was for example activated at a heat release rate of $1000 \mathrm{~kW}$ less than that in the test with the $3 \mathrm{~mm} / \mathrm{min}$ drencher system. That is a significant difference, but with the current fire growth rate such an increase would only have taken about $15 \mathrm{~s}$. When testing different active measures to protect exterior surfaces according to this method it is therefore important to have a strong criterion for activation. To show that the system can swiftly suppress a fire on the surface and hinder fire spread, there must be a significant fire established when the system is activated. A suitable criterion could for example be that the active fire protective measure should be activated:

- 45 seconds after the $30 \mathrm{~s}$ averaged uppermost (position 6) thermocouple wire reaches a gas temperature of $500^{\circ} \mathrm{C}$;

- 30 seconds after the total HRR reaches $2000 \mathrm{~kW}$; or

- 4 minutes after the $15 \mathrm{~s}$ averaged total HRR reaches $100 \mathrm{~kW}$.

For practical measurement purposes it is relevant to include some time from a certain occurrence, since the measurement systems most often include a delay. As a complement to the former two criteria it is therefore relevant to define a maximum pre-activation time in case they are not achieved. Such a criterion could be 5 minutes after the $15 \mathrm{~s}$ averaged HRR reaches $100 \mathrm{~kW}$. The actual criterion for the tested system on the other hand should be to suppress the fire, as determined for example by a significant reduction in heat release rate. The best would be if this could be compared with the level of a reference test. As of now, due to the uncertainties of the fire source according to the SP FIRE 105 test method, this would require a blank free burning run before each test to use as reference. The criterion could perhaps be combined with a more general criterion for the allowed combustion of the specimen when the system is activated. It could for example be required that the $60 \mathrm{~s}$ averaged HRR may not exceed $5-10 \%$ of the HRR in the reference test, starting from 4 minutes after activation or over the second peak. Another criterion could be that the total released energy is not allowed to exceed $5 \%$ of the reference value after this time or during the second peak. Such criteria remind of the criteria used to quantify the sample properties in the small scale test for surface flammability.

In the performed test with the passive fire protective coating, the LEO system, it was shown in Fig. 4 that the added heat release rate during the first phase of the fire was insignificant. When burning during the second phase, the addition was limited in the range of $0-10 \%$ when comparing with the reference test. The released energy during the second peak may be a suitable criterion for solutions with active measures, as this is when they are activated. However, passive systems are always "activated" and such a criterion should hence apply throughout the whole test. For example a criterion for the total released energy to not 
exceed $10 \%$ of that released in the reference test. The released energy during the tests with active and passive measures as compared with the reference test is presented in Table 3 . The tests with drencher systems (not pre-activated) were compared with the reference test over the second peak whilst the tests with the pre-activated drencher system and the fire protective coating were compared with the reference test over the whole test period. However, since there was a shift between the test with the pre-activated drencher system and the other tests, a 14 minute interval was selected to represent the each test, starting from when the HRR reached about $1000 \mathrm{~kW}$.

Table 3. Comparison of the released energy during the second peak and over the whole tests.

\begin{tabular}{|l|c|c|r|c|}
\hline Test & $\begin{array}{c}\text { Incipient time } \\
\text { cut off [min:s] }\end{array}$ & $\begin{array}{c}\text { Adjusted time } \\
\text { interval [min:s] }\end{array}$ & $\begin{array}{l}\text { Released } \\
\text { energy [MJ] }\end{array}$ & $\begin{array}{l}\text { Relative } \\
\text { difference }\end{array}$ \\
\hline Non-combustible & $2: 52$ & $8: 00-13: 30$ & 881 & - \\
\hline Non-combustible & $2: 52$ & $2: 00-16: 00$ & 1600 & - \\
\hline Drencher 2 mm & $1: 46$ & $8: 00-13: 30$ & 795 & $-9,82 \%$ \\
\hline Drencher 3 mm & $1: 56$ & $8: 00-13: 30$ & 845 & $-4,13 \%$ \\
\hline Drencher 4 mm & $1: 33$ & $8: 00-13: 30$ & 868 & $-1,53 \%$ \\
\hline Pre-activated drencher (3 mm) & $5: 19$ & $1: 10-15: 10$ & 1622 & $1,43 \%$ \\
\hline Fire protective coating (LEO) & $3: 28$ & $2: 00-16: 00$ & 1708 & $6,80 \%$ \\
\hline
\end{tabular}

The calculations of released energies in Table 3 shows that the LEO system would pass a criterion for the released energy not to exceed that produced in a reference test by more than $10 \%$. When observing Fig. 3 and Fig. 4 the HRR recordings seem quite repeatable after adjusting the starting time to when the HRR reached $100 \mathrm{~kW}$. Making such a statement therefore seems justifiable. However, from Table 3 it is apparent that the uncertainties of such a value are too large in relation to the criterion. There is for example an illogic difference of more than $8 \%$ between the tests with $2 \mathrm{~mm} / \mathrm{min}$ and $4 \mathrm{~mm} / \mathrm{min}$ drencher systems. This shows that the uncertainties are too large to give any answers regarding the suitability of the different drencher systems from such a criterion. On the other hand, the difference of $\pm 2 \%$ in some tests could be claimed rather small. However, correlating curves by adjusting the starting time to when the HRR reaches $100 \mathrm{~kW}$ also entails other problems; in a test where a long incipient phase has been cut off, more fuel will have been consumed and, as shown in Fig. 4, shifts may still appear after adjusting the time. What is more significant, as previously discussed there could be a considerable difference in the characteristics of the fire development between tests, where some follow a stage-like scenario and some have a continuous increase. Besides, the blank test run which would be necessary at least before each test series would increase the costs of the test. Many of the above problems and uncertainties could be resolved if replacing the heptane fire source according to the standard with a gas burner. It would make it far easier to adjust the levels of the fire source and a determined fire exposure could be defined with less uncertainty, for example the stagelike fire scenario discussed above. With a more defined fire source it could also be useful to have criteria regarding allowed released heat release and it would also be easier to define criteria for when an active system should be activated. A gas burner could also improve the visibility and make observations of the specimen easier during the test, which according to [23] is a problem due to the large amount of smoke produced from heptane. However, this would also change the radiation distribution over the specimen.

In addition to criteria regarding the produced heat in the test for spread of flame there is also a criterion for the maximum allowed distance of flame spread. Such a criterion also exists in SP FIRE 105 [10], where it is stated that fire may not spread to an eave at the top of the specimen. This is determined by that the gas temperature may not exceed $500^{\circ} \mathrm{C}$ for more than 2 minutes or $450^{\circ} \mathrm{C}$ for more than 10 minutes [10]. Such a requirement is very relevant to determine fire spread and could apply to either the top position or possibly position 5. Such a criterion would although only be relevant when testing passive systems, since higher requirements to also suppress a fire should apply to active measures when activated. Considering the performance of the passive LEO system it would pass such a criterion down to position 5 and the limited fire spread also corresponds with the visual observations during the test. What was also noted in the test with the LEO system was the significance of making potential joints and edges of the sample as they would appear in practice. A small fire remained in the FRP composite panel for a few minutes after the heptane had burnt out. The fire was only located along the joints between the panels and in deteriorations by surface temperature plates. Except from the remaining fire, a not insignificant part of the HRR in the previous fire may have come from pyrolysis in these areas. 


\section{CONCLUSIONS}

A test to evaluate fire spread on exterior combustible ship surfaces should capture a worst-case external fire scenario. As the fire source is often an internal fire, the stage-like scenario which appeared in the test performed based on SP FIRE 105 [10] is highly relevant. The decreasing incident radiation exposure along the height of the specimen reminds of the test for spread of flame [11, 12] but the levels are higher and the test is more severe since the specimen is also exposed to convective heat from flames. It was thus concluded that the exposure in the test method presented in SP FIRE 105 is suitable to evaluate the potential for fire growth on external combustible ship surfaces.

The results from the tests with drencher systems with different design discharge densities show that the damages caused during the minutes before activation were significant. Early activation is hence vital if FRP composite surfaces are to be protected by water application systems. Pre-activation was shown to minimize involvement of the panel; damage only appeared close to the fire source, which may be acceptable.

From the test it must be possible to evaluate whether an active measure can suppress an established worstcase fire. However, small differences in the time for activation may make a big difference in the developed HRR due to rapid fire growth at the time. It is therefore necessary to define a strong criterion for when to activate an active system which should represent when a significant fire has established. For the tested system the criterion could be that the total released energy after activation may not exceed that in a reference test by more than $5-10 \%$. For passive measures such a criterion should although apply throughout the whole test. Evaluating this criterion showed that the passive LEO system would pass such a requirement. However, the results also showed that the uncertainties are possibly too large to make any such claims. The differences in the seemingly similar HRR curves are too large and what is more, the characteristic of the fire development is known to vary even more. It was therefore suggested that the heptane fire source is replaced with a gas burner. That would also improve visibility during the test.

To evaluate the properties of the surface it could also be relevant with a criterion regarding the distance of flame spread. This could be determined by requirements on the reached gas temperatures at the top of the specimen, similar to what is required in SP FIRE 105.

In conclusion, the test method SP FIRE 105 [10] is highly suitable to evaluate fire protection of external combustible ship surfaces. A few adjustments are although recommendable and performance criteria must be further defined. As the evolution shows that the amounts of combustible shipbuilding materials on passenger ships increase [9], new types of risks are introduced. In the future the method may therefore be useful for a wider range of ships than those built in FRP composite.

\section{REFERENCES}

[1] Evegren, F., Hertzberg, T., and M. Rahm, "LASS-C; Lightweight construction of a cruise vessel", SP Report 2011:12, SP Technical Research Institute of Sweden, Borås, 2011.

[2] Hertzberg, T. (ed.), "LASS, Lightweight Construction Applications at Sea”, SP Report 2009:13, SP Technical Research Institute of Sweden, Borås, 2009.

[3] IMO, "International Convention for the Safety of Life at Sea (SOLAS)", International Maritime Organization, London, 1974.

[4] IMO, “SOLAS Consolidated Edition 2009”, International Maritime Organization, London, 2009.

[5] Evegren, F., "Assessing Fire Safety in Maritime Composite Superstructures - A Risk-Based Approach", Report 5327, Lund University, Lund, 2010.

[6] IMO, “Guidelines on Alternative Design and Arrangements for Fire Safety”, International Maritime Organization, London, 2001.

[7] Evegren, F., "Paving the way for lightweight constructions on cruise ships through the LASS-C project”, LIWEM - Proceedings of the $2^{\text {nd }}$ International conference, Gothenburg, Sweden, 28-29 March 2012, pp. 143-155.

[8] Arvidson, M., Axelsson, J., and Hertzberg, T., "Large-scale fire tests in a passenger cabin", SP Report 2008:33, SP Technical Research Institute of Sweden, Borås, 2008. 
[9] IMO, "Guidelines for evaluation of fire risk of external areas on passenger ships", MSC.1/Circ.1274, International Maritime Organization, London, 2008.

[10] SP Fire Technology, "SP Fire 105, External wall assemblies and facade claddings: Reaction to fire”, Issue No: 5, SP Technical Research Institute of Sweden, Borås, 1994.

[11] IMO, “2010 FTP Code: International Code for Application of Fire Test Procedures, 2010”, 2012 edition, International Maritime Organization, London, 2012.

[12] ISO, "Reaction to fire tests - Spread of Flame - Part 2: Lateral spread on building and transport products in vertical configuration", ISO 5658-2, Second edition, Geneva, International Organization for Standardization, 2006.

[13] Yokoi, S., "Study on the Prevention of Fire-Spread Caused by Hot Upward Current", Report of the Building Research Institute No. 34, The Building Research Institute, Ministry of Construction, Japanese Government, 1960.

[14] Ödeen, K. and Nordström, Å., "Brand- och rökspridning längs fasader och i ventilationskanaler”, (English translation: "Fire and smoke spread along façades and in ventilation ducts"), Arbetshandling 12:1967, Statens Provningsanstalt (SP Fire Technology), Borås, 1967.

[15] Ondrus, J., "Fire hazards of facades with externally applied additional thermal insulation: Full scale experiments". Report LUTVDG/(TVBB-3021), Lund Institute of Technology, Lund, 1985.

[16] Ondrus, J. and Pettersson, O., "Fire hazards of facades with externally applied additional thermal insulation: Full scale experiments". Report LUTVDG/(TVBB-3025), Lund Institute of Technology, Lund, 1986.

[17] Moss, A.G., "Facade fire spread in multi-storey buildings", BRANZ Study Report No. 32, Building Research Association of New Zeeland, Judgeford, 1990.

[18] Abecassis Empis, C., "Analysis of the compartment fire parameters influencing the heat flux incident of the structural façade", $\mathrm{PhD}$ thesis, University of Edinbourgh, Edinbourgh, 2010.

[19] Jansson, R. and Anderson, J., "Experimental and numerical investigation of fire dynamics in a façade test rig", Proceedings of Fire Computer Modeling, Santander, Spain, 18-19 October 2012, p. 247.

[20] Hildebrand, C., "Façade Fire Testing”, Workshop report CIB 14, Institut für Baustoffe, Leipzig, 1988.

[21] Johannesson, P. and Larsson, G., "Fire Tests with light, non-bearing external walls", Meddelande 124, Statens Provningsanstalt (SP Fire Technology), Borås, 1958.

[22] Hermodsson, T. and Månsson L., "Facades: Fire testing of materials and constructions: a first proposal for a test method", SP AR 1992:64, SP Fire Technology, 1992.

[23] Babrauskas, V., (1996) Façade Fire Tests: Towards an International Test Standard, Fire Technology 32: 219-230.

[24] Van Hees, P., "Semi-natural fire test for facades and curtain walling systems”, SP AR 2000:39, SP Fire Technology, 2000.

[25] Holman, J.P., et al., Heat Transfer, C., McGraw-Hill, New York 1986.

[26] Häggkvist, A., Sjöström, J. and Wickström, U., (2013) Using plate thermometer measurements to calculate incident heat radiation, Journal of Fire Sciences 31: 166-177.

[27] IMO, “International Code of Safety for High-Speed Craft”, International Maritime Organization, London, 2000.

[28] ISO, "Reaction-to-fire tests - Full-scale room tests for surface products", ISO 9705:1993, Geneva, International Organization for Standardization, 1993. 